\title{
Evaluation of CHIRPS Satellite Gridded Dataset as an Alternative Rainfall Estimate for Localized Modelling over Uganda
}

\author{
Ivan Bamweyana, Moses Musinguzi, Lydia Mazzi Kayondo \\ Department of Geomatics and Land Management, Makerere University, Kampala, Uganda \\ Email: ivanson5@gmail.com
}

How to cite this paper: Bamweyana, I., Musinguzi, M., and Kayondo, L.M. (2021) Evaluation of CHIRPS Satellite Gridded Dataset as an Alternative Rainfall Estimate for Localized Modelling over Uganda. Atmospheric and Climate Sciences, 11, 797-811. https://doi.org/10.4236/acs.2021.114046

Received: August 15, 2021

Accepted: October 26, 2021

Published: October 29, 2021

Copyright $\odot 2021$ by author(s) and Scientific Research Publishing Inc. This work is licensed under the Creative Commons Attribution International License (CC BY 4.0).

http://creativecommons.org/licenses/by/4.0/

\begin{abstract}
The Ugandan economy is largely dependent on rural-based and rain-fed agriculture. This creates a critical need to understand the rainfall dynamics at the local scale. However, the country has a sternly sparse and unreliable rain gauge network. This research, therefore, sets out to evaluate the use of the CHIRPS satellite gridded dataset as an alternative rainfall estimate for local modelling of rainfall in Uganda. Complete, continuous and reliable in situ station observations for the period between 2012 and 2020 were used for the comparison with CHIRPS satellite data models in the same epoch. Rainfall values within the minimum $5 \mathrm{~km}$ and maximum $20 \mathrm{~km}$ radii from the in situ stations were extracted at a $5 \mathrm{~km}$ interval from the interpolated in situ station surface and the CHIRPS satellite data model for comparison. Results of the $5 \mathrm{~km}$ radius were adopted for the evaluation as it's closer to the optimal rain gauge coverage of $25 \mathrm{~km}^{2}$. They show the $\mathrm{R}^{2}=0.91, \mathrm{NSE}=0.88, \mathrm{PBias}=-0.24$ and RSR $=$ 0.35. This attests that the CHIRPS satellite gridded datasets provide a good approximation and simulation of in situ station data with high collinearity and minimum deviation. This tallies with related studies in other regions that have found CHIRPS datasets superior to interpolation surfaces and sparse rain gauge data in the comprehensive estimation of rainfall. With a $0.05^{\circ} * 0.05^{\circ}$ (Latitude, longitude) spatial resolution, CHIRPS satellite gridded rainfall estimates are therefore able to provide a comprehensive rainfall estimation at a local scale. Essentially these results reward research science in regions like Uganda that have sparse rain gauges networks characterized by incomplete, inconsistent and unreliable data with an empirically researched alternative source of rainfall estimation data. It further provides a platform to scientifically interrogate the rainfall dynamics at a local scale in order to infuse local policy with evidence-based formulation and application.
\end{abstract}




\section{Keywords}

Spatial Statistics, CHIRPS, Satellite Gridded Dataset, Rainfall Estimates

\section{Introduction}

Precipitation is one of Uganda's most critical and valuable resources. Its availability and variability have direct implications on the country's overall development given the predominance of rain-fed agriculture [1]. Indeed, rain-fed agriculture and agriculture-related production are vital to the Ugandan economy; they averagely employ $80 \%$ of the labour force, account for $42 \%$ of the GDP, and bring in $90 \%$ of export earnings [2] [3]. However, Uganda is in the deficit of a dense rain gauge network and long-term in situ precipitation measurements are required for detailed assessment of her rainfall [4] [5]. The rain fall records are typical of non-continuity with only a few years of quality data, sparse rain gauge network, incomplete, inconsistent and non-reliable datasets. Notably, understanding the dynamics of climate variations and extremes that are consistent with the region requires long-term accurate precipitation data representations and a dense network of in situ observation stations [6] [7]. The World Meteorological Organization (WMO) set the classical period of assessing climate variability to 30 years.

Research [8] puts the optimum rain gauge network density between $14 \mathrm{~km}^{2} /$ gauge and $38 \mathrm{~km}^{2}$ /gauge, with an average of $25 \mathrm{~km}^{2} /$ gauge. With Uganda having a total area of $241,550 \mathrm{~km}^{2}$, this puts the total gauge requirement per $25 \mathrm{~km}^{2}$ close to about 9500 weather stations. However, as of 2013, Uganda had 21 weather stations [9]. With the proliferation of automated weather stations, as of 2021, the total number of weather stations had been improved to 37. Incidentally, of these, 25 are working, 7 were vandalized and 5 had power problems. This puts the total landmass covered to $625 \mathrm{~km}^{2}$ out of the total $241,550 \mathrm{~km}^{2}$, accounting for only $0.0026 \%$ gauge coverage. This has characterized the country with a critically sparse and unreliable rain gauge network. Traditionally, it should be noted that set rain gauges are affected by animal and human interference, uncalibrated measuring mechanisms, level placement, wind, poor monitoring and evaporation [10] [11] [12]. This further worsens the dependency on completeness and consistency of in situ measurements from rain gauges. Also, relative to satellites that can provide precise measurements at every location, for developing countries, the sparsely distributed weather stations are characterized by poor coverage for rural areas and require interpolation between stations [13] to relay general coverage of a region. This makes the reliance on satellite data sets inevitable to achieve alternative estimates of rainfall with adequate sampling density, accuracy, completeness and reliability. However, satellite-based precipitation estimates are often not assessed for integration into operational and decision-making applications due to the lack of empirical research on their uncertainty and reliability [14]. For Uganda, 
no explicit countrywide empirical research has been done to assess the suitability of satellite gridded precipitation datasets as an alternative rainfall estimate at a local scale. It should be noted that the region is challenged with scarce and inconsistent precipitation data. The objective of this research was, therefore, to evaluate satellite gridded datasets as an alternative rainfall estimate for modelling rainfall at a local scale. The research will enable satellite-based precipitation estimates to be integrated into the operational analysis of rainfall dynamics as a proxy for in situ rainfall data in Uganda.

\section{Satellite Gridded Datasets as Alternative Rainfall Estimates}

Numerous satellite gridded precipitation data sets exist at a global and regional scale [15]. Though satellites have trouble measuring some ground phenomena such as precipitation as compared to weather stations, they provide a more complete spatial coverage of various parameters over a landscape [13]. This has prompted research to understand the contrast between the two sets of data. Throughout the literature, several studies have compared satellite remote sensing products to in situ data [16] [17] [18] [19] [20]. The satellite-based datasets have generally presented a better performance at annual and seasonal scales. Some scholars [21], explored the performance of stochastic models for spatial rainfall downscaling to reproduce statistics for precipitation observable at a local scale. The analysis, however, would not allow preference among the studied models. Other scholars [22] have explored algorithms of blending the in situ measurements with satellite observations to derive more accurate products for local rainfall analytics. However, none of the research has been conclusive leaving a gap in the analysis of local precipitation using satellite gridded rainfall estimation datasets.

\section{Materials and Methods}

\subsection{Study Area}

This research was carried out within the spatial domain of the Republic of Uganda. Uganda is a landlocked country in the eastern part of Africa and lies within the northern and southern hemispheres, being crossed by the Equator. Neighboring countries are Kenya to the East, South Sudan to the North, the United Republic of Tanzania and Rwanda to the South and the Democratic Republic of Congo to the West. According to [23], the country has a total surface area of $241,550 \mathrm{~km}^{2}$ of which $41,743 \mathrm{~km}^{2}(17.2 \%)$ is occupied by open water and swamps, and $199,807 \mathrm{~km}^{2}$ is open land. Uganda is a plateau surrounded by four main mountain ranges; namely: Rwenzori in the west (with a peak of $5110 \mathrm{~m}$ ), Elgon in the East, Mufumbira in the Southwest, and Moroto in the Northeast. The lowest part is within the Albert Nile at $620 \mathrm{~m}$ above sea level. This topographic complexity is associated with a high density of micro-environments where climatic variables become difficult to study [24]. In essence, this makes the area suitable 
for this study relative to other gauge complexities. The map in Figure 1 shows the location of Uganda in Africa, its administrative districts and large water bodies.

\subsection{Rainfall Data Sets}

\subsubsection{Satellite Gridded Data Sets}

The Climate Hazards Group InfraRed Precipitation with Stations (CHIRPS) data set was used as the proxy for satellite gridded datasets. The datasets blend station precipitation data with infrared Cold Cloud Duration (CCD) at $0.05^{\circ} * 0.05^{\circ}$ (latitude, longitude) spatial resolution [25]. It has been adopted for this research mainly for three reasons: 1) It has high sub-regional suitability in comparison to other precipitation satellite products [26] [27] [28]; 2) It has substantial improvement over non resampled satellite products due to gauge based bias correction [29]; 3) Other alternative satellite products offer a coarse spatial resolution; Global Precipitation Climatology Project (GPCP) and the Climate Precipitation Centre (CPC) Merged Analysis of Precipitation (CMAP) have a $2.5^{\circ} * 2.5^{\circ}$

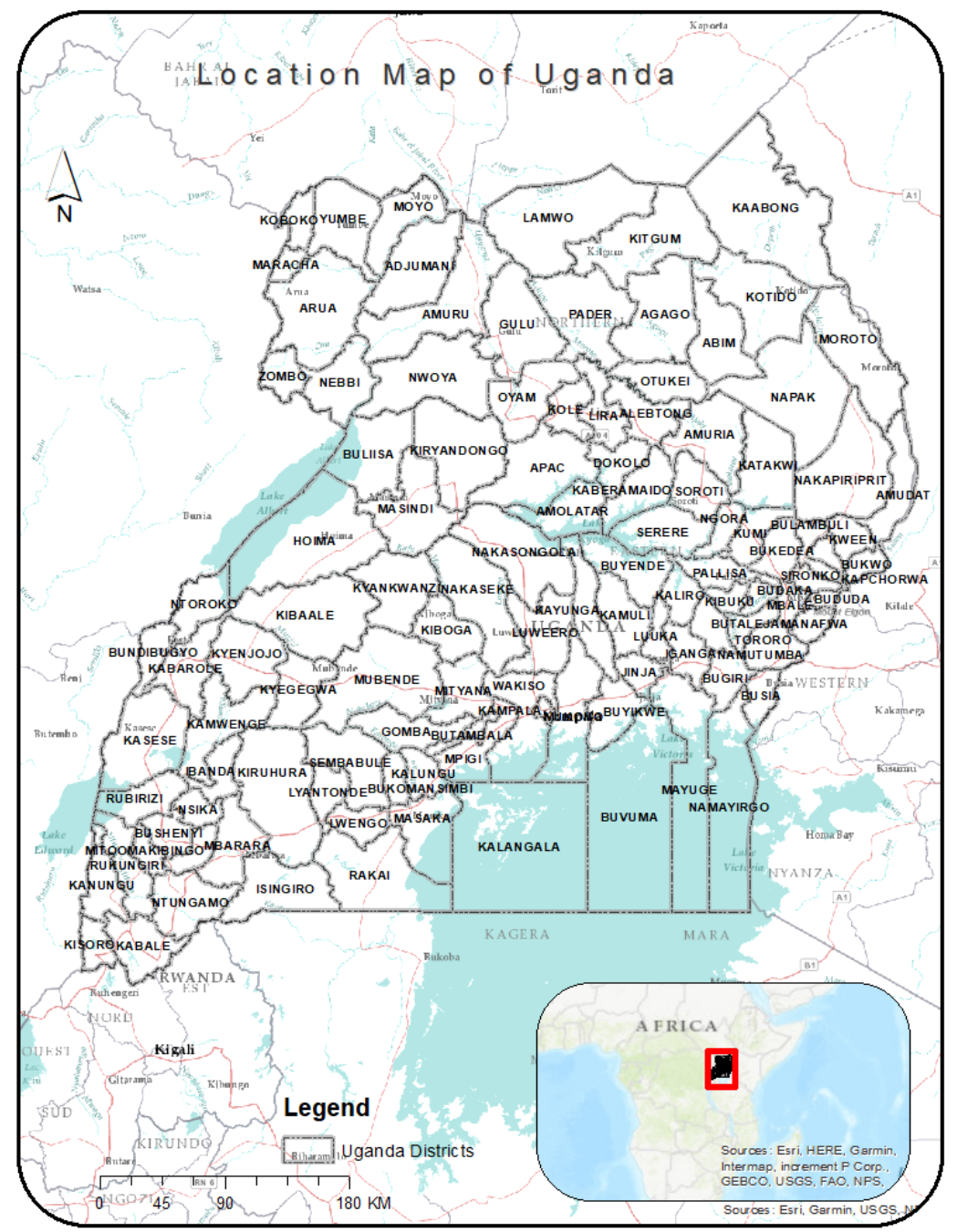

Figure 1. Location map of Uganda. 
spatial resolution while the African Rainfall Climatology version 2 (ARC2) and Tropical Rainfall Measuring Mission (TRMM) have a spatial resolution of $0.1^{\circ}$ * $0.1^{\circ}$ and $0.25^{\circ} * 0.25^{\circ}$ respectively.

\subsubsection{In Situ Measurements}

In Situ precipitation data was gotten from Uganda National Meteorological Authority (UNMA). The data was for multiple weather stations. However, the datasets were assessed for completeness, continuity, consistency, and reliability. On this basis, only 12 of the 25 data stations were utilized. Their distribution is illustrated in Figure 2. Though long time series are often required, the datasets used in this research were for the temporal period of 2012 to 2020 . Beyond this period there were no sufficient datasets that fulfilled the criteria suitable for effective comparison with the gridded datasets.

\section{Statistical Metrics}

Spatial Inference research on precipitation studies has utilized a vast continuum of statistical criteria to assess agreement between models [24] [27] [28]. This research adopted the statistical metrics shown in Table 1.

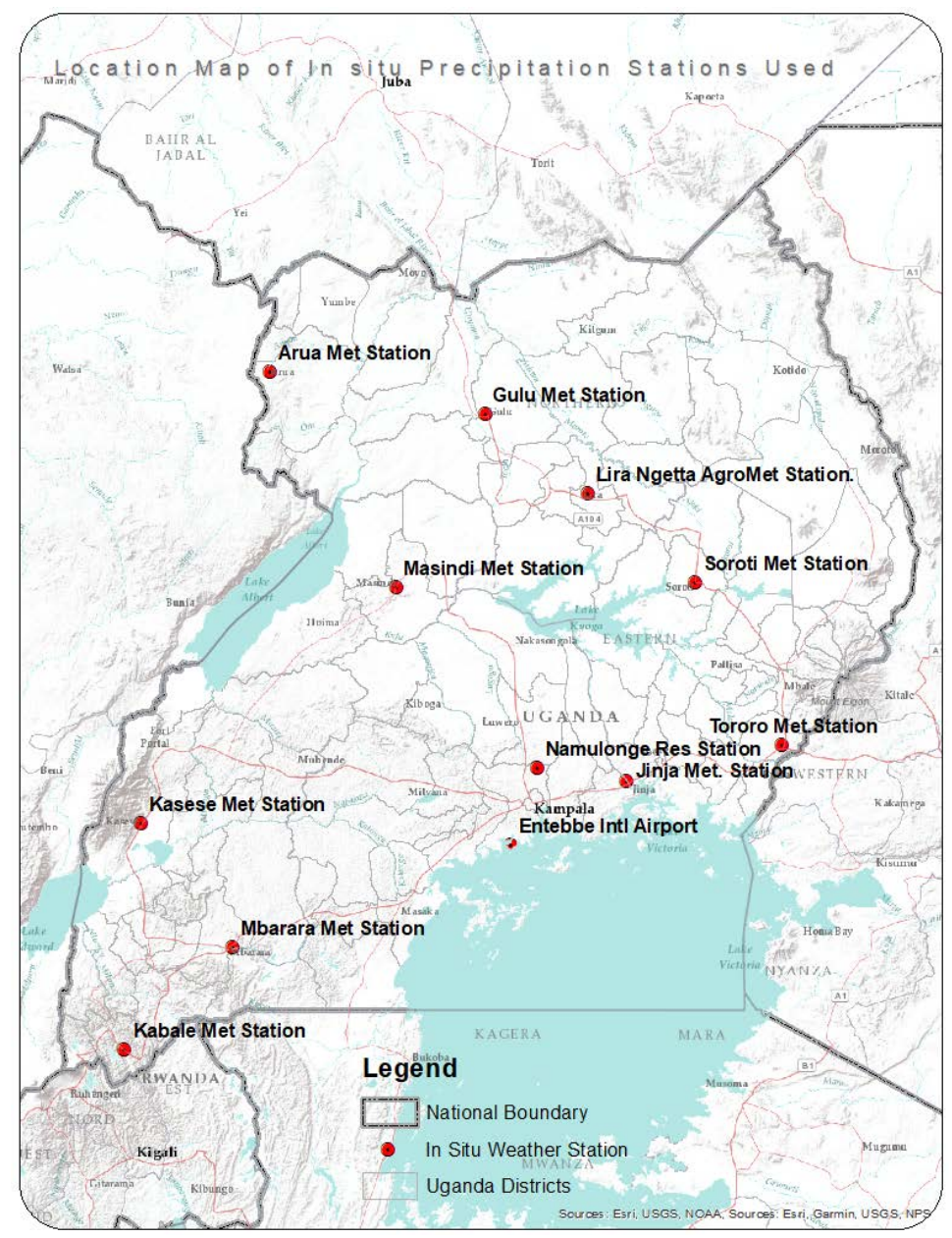

Figure 2. Location map of the in situ precipitation stations. 
Table 1. Adopted statistical metrics.

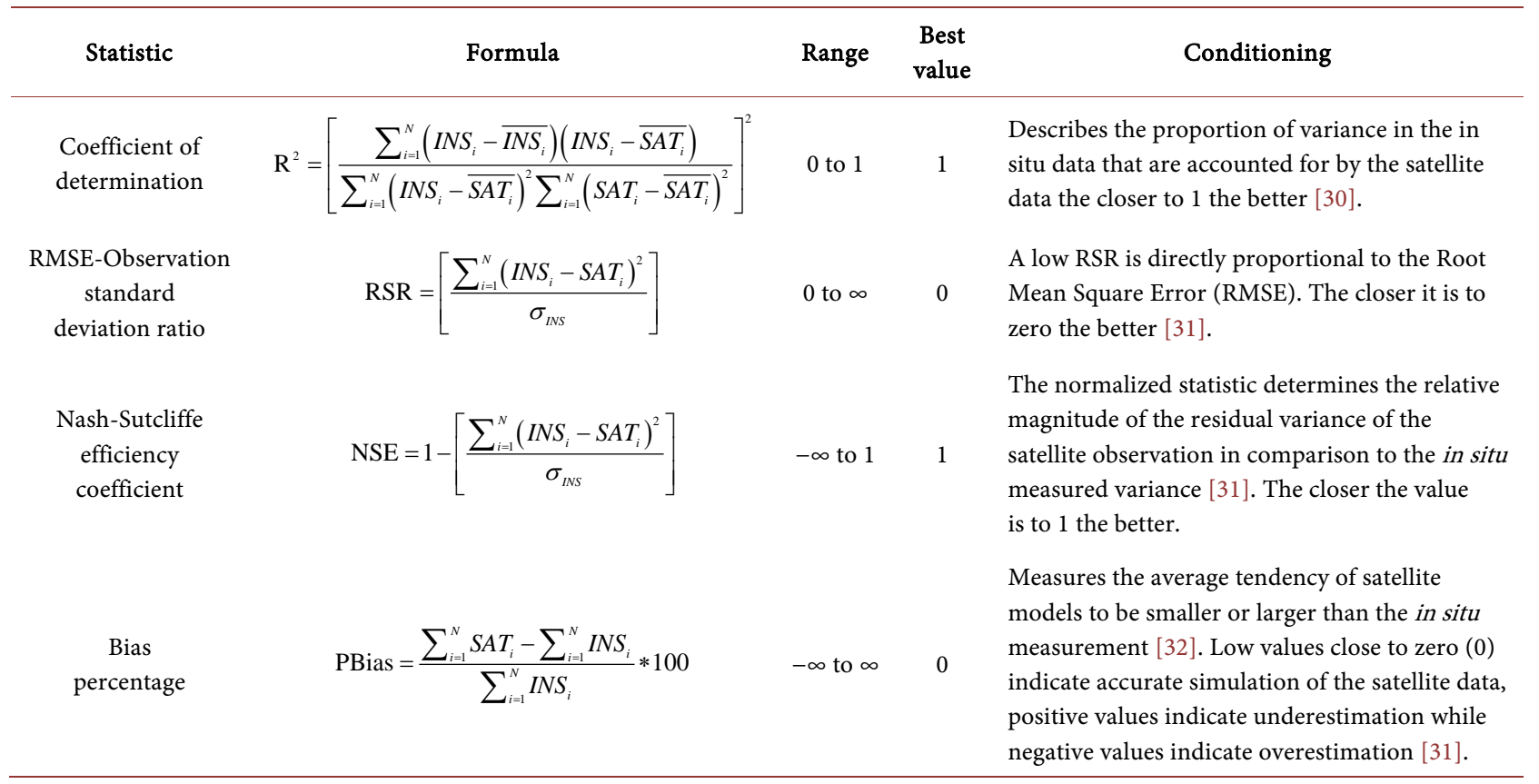

\section{Methodology (Figure 3)}

Datasets collected from the weather stations were assessed for consistency, completeness and continuity for the study period between 2012 and 2020. The data were interpolated between stations across the country. The validity of the resulting interpolation was assessed through independent weather stations (15\% of the original weather stations) repetition were used to validate the Interpolation. The geostatistical ordinary Kriging was used as previous studies showed that it achieved the best results in precipitation interpolation [24] [33]. A fishnet was generated over Uganda with a $5 \mathrm{~km}$ point grid. Buffers of $5 \mathrm{~km}$ to $20 \mathrm{~km}$ from the in situ measurement stations were generated to clip the points of the fishnet. The clipped points were used for the extraction of values from the interpolated surface and satellite gridded dataset (CHIRPS). A bivariate linear regression was run between the extracted values of the interpolation surface and the CHIRPS surface in iteration to acquire the best sample points extraction range for comparing the two surfaces at an $\mathrm{R}^{2}$ greater than 0.75 . This was in consideration of [8] analysis on optimal distance for in situ station coverage. Buffers of $5 \mathrm{~km}$ and $20 \mathrm{~km}$ were chosen as the furthest and nearest ranges for further analysis of the comparison between the CHIRPS satellite gridded dataset and in situ station measurement rainfall estimates (the minimum $5 \mathrm{~km}$ range was chosen because the CHIRPS has a $0.05^{\circ} * 0.05^{\circ}$ (latitude, longitude) spatial resolution). These were subjected to further spatial statistical metrics shown in Table 1 to derive a detailed evaluation of the relation between the two surfaces.

\section{Results and Discussion}

Precipitation data from the in situ weather stations was mapped by Kriging 


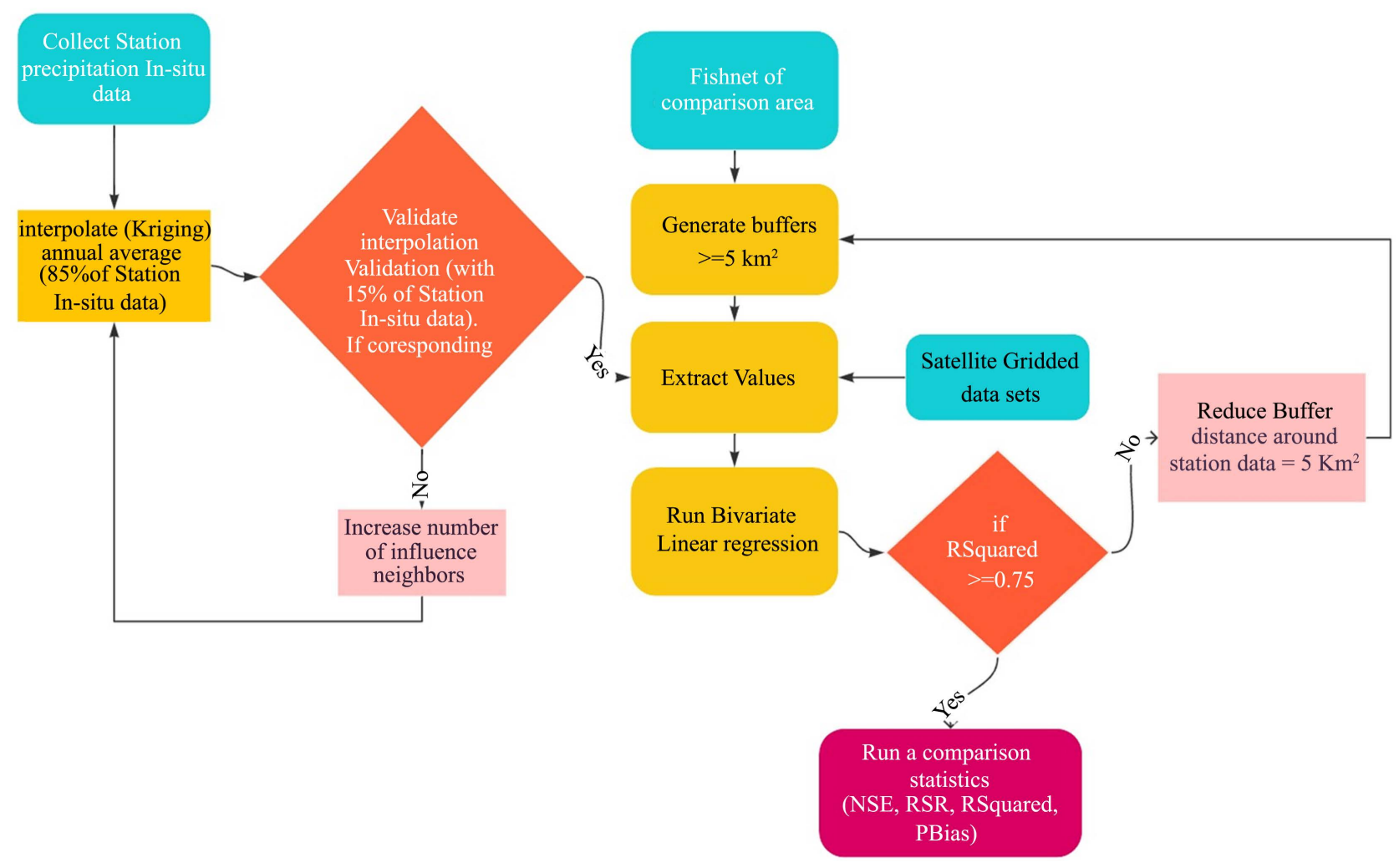

Figure 3. Methodology flow diagram.

interpolation for each year as shown in Figure 4. The results showed an average representation of most precipitation being received along the northwest-southeast belt and the Lake Victoria basin. From the results, it can also be deduced that the southwest-northeast belt received less rainfall. This is consistent with observations of the cattle corridor that show a pronounced increase in dry spells along the southwest-northeast corridor [34]. Related research [35] also observed the highest rainfall in the north-west and central east of Uganda and Lake Victoria vicinity

Satellite gridded datasets were collected for the same epoch (2012-2020) as the in situ data sets and mapped as shown in Figure 5. Similar to observations by [35] the lowest precipitation totals are in the northeast (Karamoja region) and the south-west while the highest levels of precipitation are observed in the Lake Victoria vicinity, central-east and north-west.

Research [8] approximates optimal rain gauge coverage to about $25 \mathrm{~km}^{2}$ beyond which the quality of representation drops. From the in situ measurement positions in Figure 2, buffers points at $5 \mathrm{~km}$ intervals were generated as shown in Figure 6 for extraction of values from each surface at minimum $5 \mathrm{~km}$ and maximum $20 \mathrm{~km}$ ranges.

Between the in situ and satellite observations at $5 \mathrm{~km}$, the coefficient of determination $\left(\mathrm{R}^{2}\right)$ showed very strong collinearity of 0.91 as shown in Figure 7. The Nash-Sutcliffe Efficiency (NSE) coefficient $=0.88$, Percentage of Bias $($ PBias $)=$ -0.24 , and the RMSE-observations Standard deviation Ratio $(\mathrm{RSR})=0.35$. 


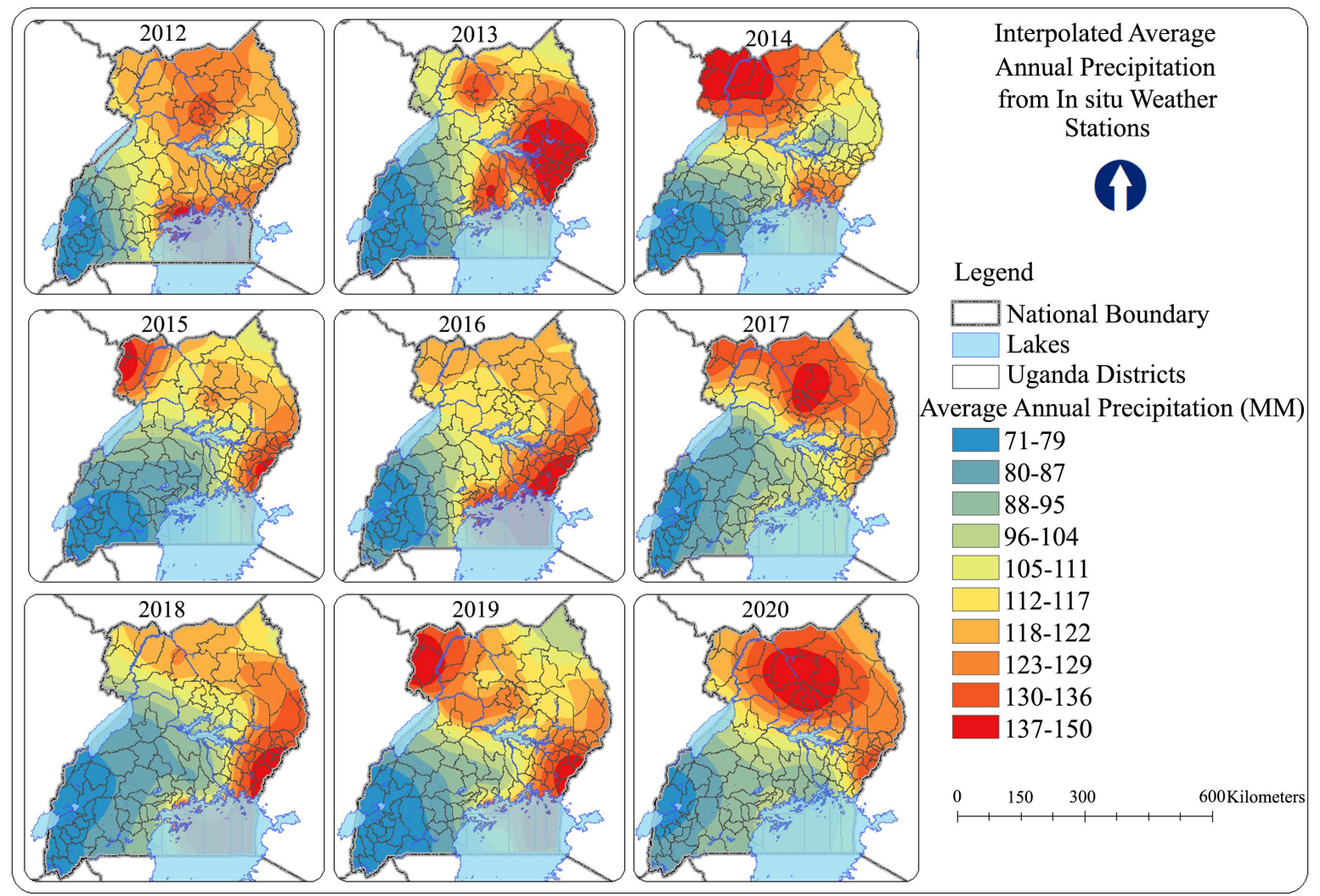

Figure 4. Interpolated average annual precipitation.

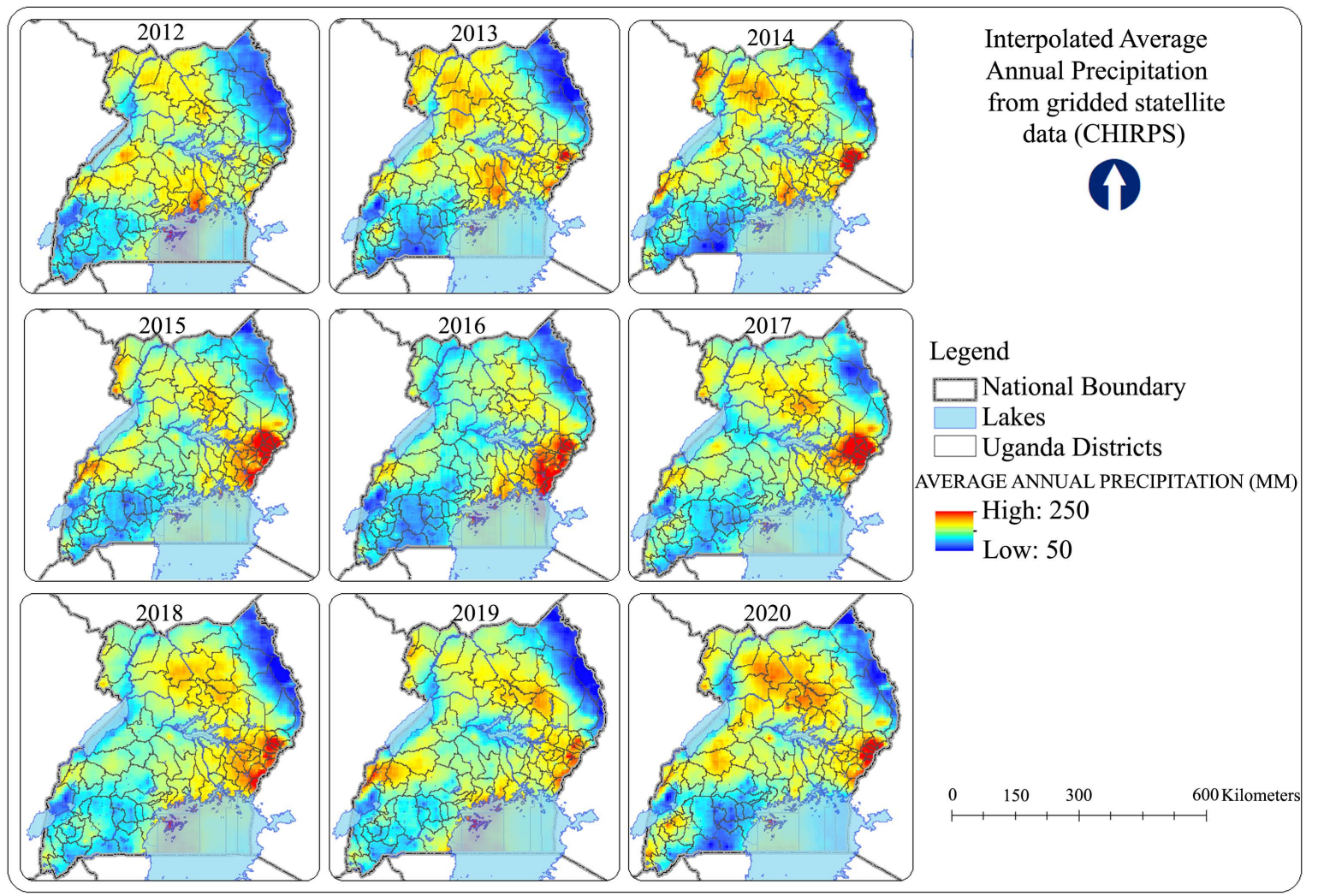

Figure 5. Average annual precipitation from satellite gridded data sets-CHIRPS. 

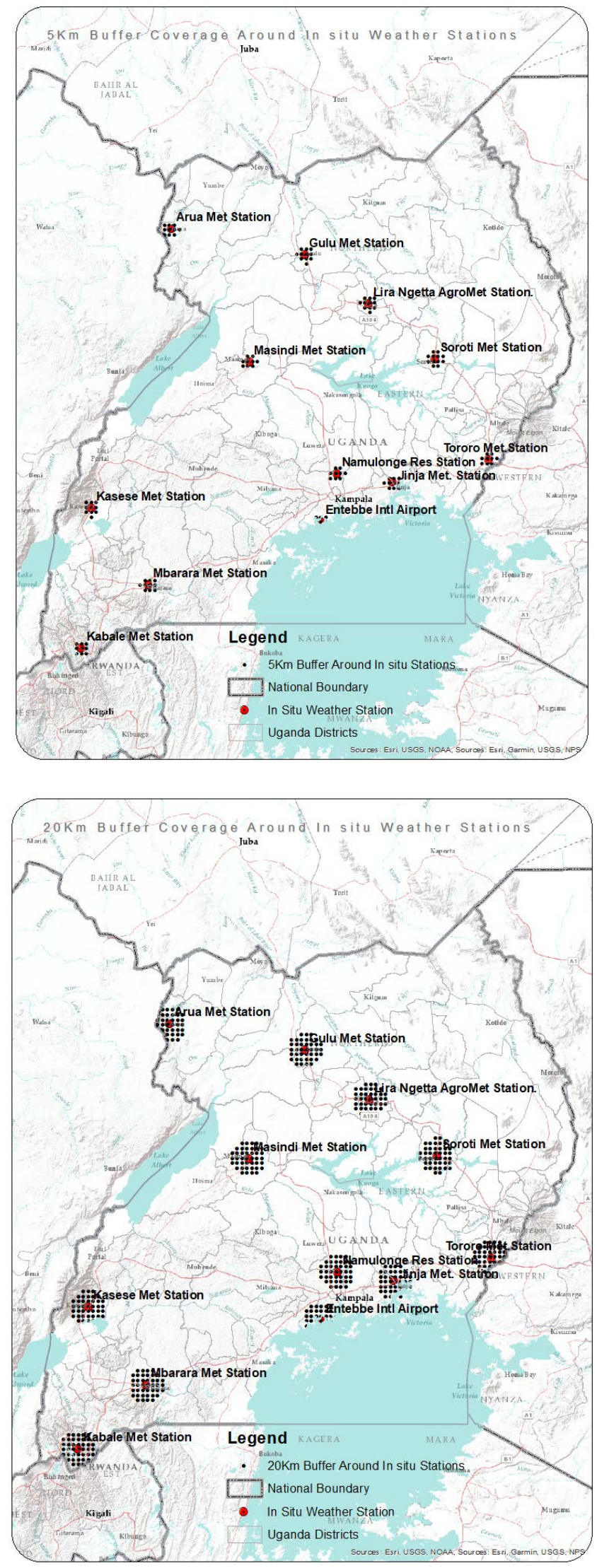

Figure $6.5 \mathrm{~km}$ and $20 \mathrm{~km}$ sample range. 


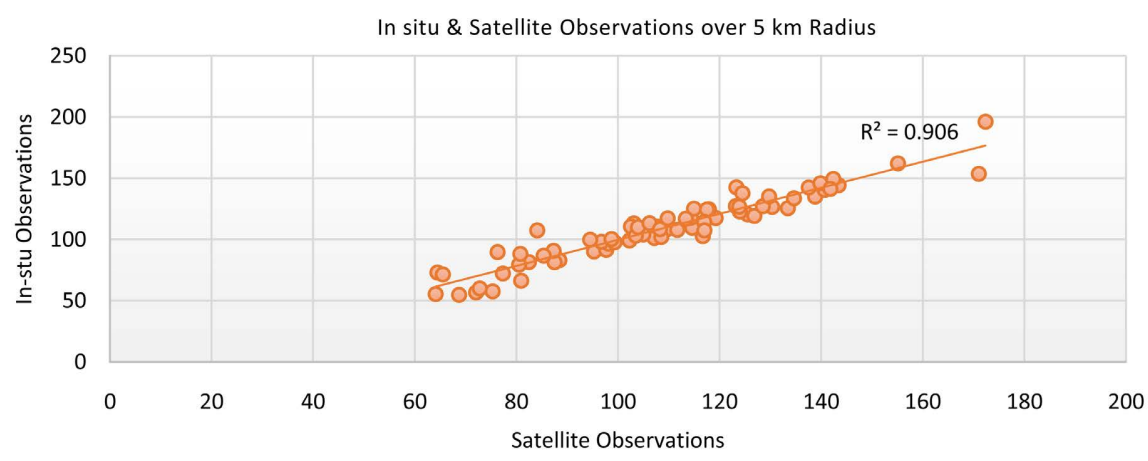

Figure 7. Collinearity between in situ and satellite precipitation observations within a 5 $\mathrm{km}$ radius of the weather station.

Between the in situ and satellite observations at $20 \mathrm{~km}$, the coefficient of determination $\left(\mathrm{R}^{2}\right)$ showed strong collinearity of 0.75 as shown in Figure 8. The Nash-Sutcliffe Efficiency $($ NSE) coefficient $=0.461$, Bias Percentage $($ PBias $)=$ 0.84 , and the RMSE-observations Standard deviation Ratio (RSR) $=0.51$.

Several studies [36] [37] have adopted the performance rating of the statistical metrics $\mathrm{R}^{2}$ [30], and RSR, NSE, PBias [31] shown in Table 2. According to this rating, at $5 \mathrm{~km}$ there is very good collinearity between the in situ data and the CHIRPS satellite model with an $\mathrm{R}^{2}$ of 0.91 . This implies that a high proportion of the variance in the in situ observations is accounted for in the CHIRPS gridded satellite observations. The RSR of 0.35 low value at $5 \mathrm{~km}$ indicates a very good approximation by the CHIRPS satellite model. The 0.88 NSE also implies a very good simulation of in situ data by the CHIRPS satellite data. The PBias of -0.24 indicates minimal deviation of the data being evaluated which also accounts for the very good simulation by the CHIRPS model. At $20 \mathrm{~km}$ an $\mathrm{R}^{2}$ of 0.75 indicated a good collinearity between the in situ and satellite observation. The RSR of 0.51 also indicated a good approximation of the in situ data by the CHIRPS satellite model. The PBias of 0.84 also indicated an acceptable deviation between the in situ data and the gridded satellite data. However, the NSE of 0.461 indicated an unsatisfactory simulation of the in situ data by the CHIRPS satellite model.

Similar statistical metrics were run for each of the in situ stations and its $5 \mathrm{~km}$ and $20 \mathrm{~km}$ radius as shown in Table 3 . Within the $5 \mathrm{~km}$ radius, $75 \%$ of the stations presented with an R2 above 0.86 indicating very good collinearity between the in situ observations and CHIRPS satellite data model. However, the Kabale station presented an unsatisfactory $\mathrm{R}^{2}$ of 0.44 . Also, $60 \%$ of the stations indicated an above satisfactory RSR statistic indicating a good approximation of the in situ data by the CHIRPS satellite data model. Correspondingly, $65 \%$ of the stations presented an NSE statistic above satisfactory indicating an acceptable simulation of in situ data by CHIRPS satellite gridded data. All the stations had above satisfactory PBias indicating acceptable deviation between the two datasets. At 20 $\mathrm{km}$, only $25 \%$ of the records presented R2 and RSR above satisfactory levels indicating low levels of collinearity and approximation between the models, $40 \%$ 


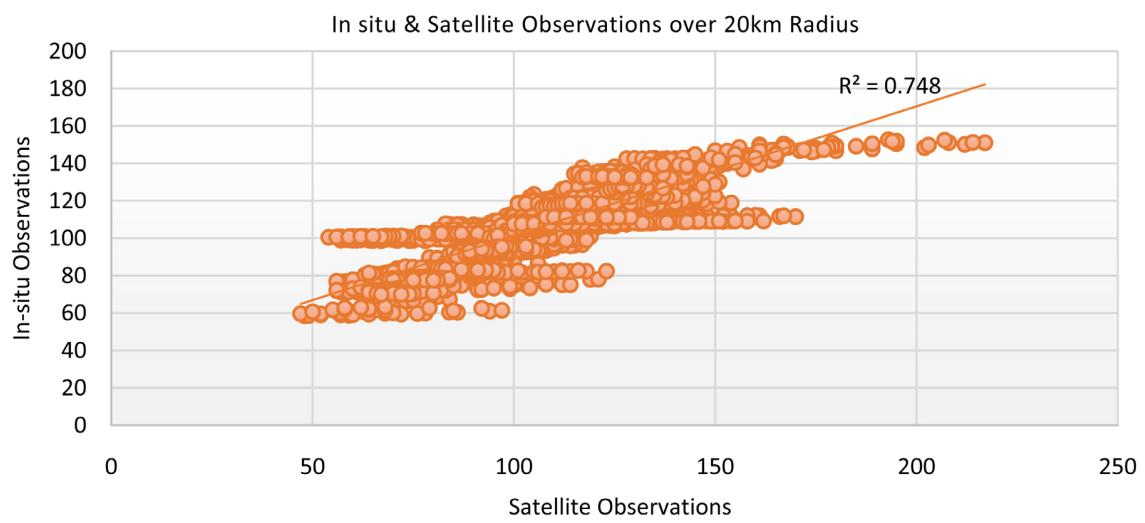

Figure 8. Collinearity between in situ and satellite precipitation observations within a 20 $\mathrm{km}$ radius of the weather station.

Table 2. Performance rating of the statistical metrics.

\begin{tabular}{ccccc}
\hline $\begin{array}{c}\text { Performance } \\
\text { Rating }\end{array}$ & RSR & NSE & PBIAS & R $^{2}$ \\
\hline Very Good & $0.00 \leq \mathrm{RSR} \leq 0.50$ & $0.75 \leq \mathrm{NSE} \leq 1$ & PBIAS $< \pm 10$ & $0.86<\mathrm{R}^{2} \leq 1$ \\
Good & $0.60<\mathrm{RSR} \leq 0.50$ & $0.65<\mathrm{NSE} \leq 0.75$ & $\pm 10 \leq \mathrm{PBIAS} \leq \pm 15$ & $0.75<\mathrm{R}^{2} \leq 0.86$ \\
Satisfactory & $0.70<\mathrm{RSR} \leq 0.60$ & $0.50<\mathrm{NSE} \leq 0.65$ & $\pm 15 \leq \mathrm{PBIAS} \leq \pm 25$ & $0.65<\mathrm{R}^{2} \leq 0.75$ \\
Unsatisfactory & $\mathrm{RSR}>0.7$ & $\mathrm{NSE} \leq 0.50$ & $\mathrm{PBIAS} \leq \pm 25$ & $\mathrm{R}^{2} \leq 0.65$ \\
\hline
\end{tabular}

Table 3. Statistical metrics at $5 \mathrm{~km}$ and $20 \mathrm{~km}$ sample range of in situ weather stations.

\begin{tabular}{ccccccccc}
\hline & \multicolumn{3}{c}{$\begin{array}{c}\text { Statistical Metrics at } \\
\text { 5 km Per Station }\end{array}$} & \multicolumn{3}{c}{ Statistical Metrics at } \\
& \multicolumn{3}{c}{ 20 km Per Station } \\
\hline In Situ Station & NSE & PBIAS & $\mathbf{R}^{2}$ & RSR & NSE & PBIAS & R $^{2}$ & RSR \\
\hline Arua & 0.88 & 0.17 & 0.88 & 0.35 & 0.16 & -0.58 & 0.46 & 0.92 \\
Entebbe & 0.91 & -1.75 & 0.97 & 0.3 & 0.5 & 6.18 & 0.62 & 0.71 \\
Gulu & 0.24 & 4.1 & 0.89 & 0.87 & 0.46 & 3.24 & 0.64 & 0.74 \\
Jinja & 0.63 & -1.56 & 0.66 & 0.61 & 0.69 & 2.48 & 0.76 & 0.55 \\
Kabale & -0.04 & -8.64 & 0.41 & 1.02 & -0.01 & -6.13 & 0.5 & 1 \\
Kasese & 0.82 & 2.79 & 0.87 & 0.43 & -0.51 & -7.18 & 0.02 & 1.23 \\
Lira & 0.34 & -8.91 & 0.9 & 0.81 & 0.45 & 3.21 & 0.67 & 0.74 \\
Masindi & 0.71 & -4.48 & 0.95 & 0.54 & 0.66 & -3.45 & 0.77 & 0.59 \\
Mbarara & 0.89 & 0.31 & 0.92 & 0.33 & 0.05 & -6.33 & 0.53 & 0.97 \\
Namulonge & -6.24 & 19.08 & 0.74 & 2.69 & 0.58 & 2.78 & 0.63 & 0.65 \\
Soroti & 0.47 & 5.36 & 0.94 & 0.73 & 0.22 & -1.95 & 0.57 & 0.88 \\
Tororo & 0.96 & -0.89 & 0.97 & 0.21 & 0.08 & 10.26 & 0.47 & 0.96 \\
\hline
\end{tabular}

of the stations presented an NSE statistic above satisfactory level implying that more than $60 \%$ of the in situ observation couldn't be interpreted at this range. However, the PBIAS indicated acceptable deviations between the two models. 


\section{Conclusion}

The assessments and monitoring of precipitation variation, changes and extremes are critical to an agriculturally based economy. However, for Uganda, the availability of consistent, complete, and reliable precipitation data required for this monitoring and assessment has remained a challenge. This research sets out to validate the use of CHIRPS satellite gridded data sets as an alternative source of precipitation data. Based on the [8] review of best rainfall in situ observations being in the optimal range of $25 \mathrm{~km}^{2}$, this research forms an evaluation basis to validate the use of CHIRPS satellite gridded dataset as an alternative precipitation estimation dataset by comparing the $5 \mathrm{~km}$ range and radius sample points between surfaces of interpolated in situ surfaces and CHIRPS satellite dataset. It further shows that widening the validation area beyond the optimal coverage of the rain gauge generates dwindling effects on the validation between the in situ and CHIRPS satellite gridded dataset surfaces. Spatially based statistical metrics that include the coefficient of determination $\left(\mathrm{R}^{2}\right)$, the Nash-Sutcliffe Efficiency coefficient (NSE), Bias Percentage (PBias), the RMSE-observations and the Standard deviation Ratio (RSR) were used to check collinearity, simulation, deviation and approximation respectively between the two rain estimation models. General results indicate that the $\mathrm{R}^{2}=0.91, \mathrm{NSE}=0.88, \mathrm{PBias}=-0.24$ and $\mathrm{RSR}=0.35$. This attests that the CHIRPS Satellite gridded datasets provide a good approximation and simulation of in situ station data with high collinearity and minimum deviation. This can be attributed to the spatial resolution and temporal resolution of the CHIRPS dataset as well as its gauge bias correction. The results tally with related studies [27] in other regions that have found CHIRPS datasets superior to interpolation surfaces and sparse rain gauge data in the comprehensive estimation of rainfall. With a $0.05^{\circ} * 0.05^{\circ}$ (latitude, longitude) spatial resolution, CHIRPS satellite gridded rainfall estimates are able to provide rainfall representation at a local scale. Essentially these results reward research science in regions like Uganda that have sparse rain gauges networks characterized by incomplete, inconsistent and unreliable data with an empirically researched alternative source of rainfall data. It further provides a platform to interrogate the rainfall dynamics at a local scale in order to infuse local policy with evidence-based formulation and application.

\section{Conflicts of Interest}

The authors declare no conflicts of interest regarding the publication of this paper.

\section{References}

[1] Republic of Uganda (2012) The 2010-2011 Integrated Rainfall Variability Impacts, Needs Assessment and Drought Risk Management Strategy.

[2] Matthews, G.A. and Bateman, R.P. (1990) Application Techniques for Small-Scale Farmers. In: Grayson, B.T., Green, M.B. and Copping, L.G., Eds., Pest Management 
in Rice, Springer, Berlin, 421-429. https://doi.org/10.1007/978-94-009-0775-1 34

[3] Uganda National Adaptation Programme of Action (NAPA) (2007) National Adaptation Programme of Action National Adaptation Programme of Action under the United Nations Framework Convention on Climate Change (UNFCCC). The Republic of Uganda, Ministry of Environment. Land, 4, 421-429.

[4] Diem, J.E., Hartter, J., Ryan, S.J. and Palace, M.W. (2014) Validation of Satellite Rainfall Products for Western Uganda. Journal of Hydrometeorology, 15, 2030-2038. https://doi.org/10.1175/JHM-D-13-0193.1

[5] Nsabagwa, M., Byamukama, M., Otim, J.S. and Okou, R. (2016) Network Densification Strategies for Automatic Weather Stations: Challenges and Opportunities for Uganda. 2016 IST-Africa Conference, Durban, 11-13 May 2016, 1-8. https://doi.org/10.1109/ISTAFRICA.2016.7530633

[6] Iqbal, Z., Shahid, S., Ahmed, K., Ismail, T. and Nawaz, N. (2019) Spatial Distribution of the Trends in Precipitation and Precipitation Extremes in the Sub-Himalayan Region of Pakistan. Theoretical and Applied Climatology, 137, 2755-2769. https://doi.org/10.1007/s00704-019-02773-4

[7] Xu, Z. and Yang, Z.L. (2012) An Improved Dynamical Downscaling Method with GCM Bias Corrections and Its Validation with 30 Years of Climate Simulations. Journal of Climate, 25, 6271-6286. https://doi.org/10.1175/JCLI-D-12-00005.1

[8] Gyasi-Agyei, Y. (2020) Identification of the Optimum Rain Gauge Network Density for Hydrological Modelling Based on Radar Rainfall Analysis. Water (Switzerland), 12, 1906. https://doi.org/10.3390/w12071906

[9] Mugume, I., et al. (2018) Improving Quantitative Rainfall Prediction Using Ensemble Analogues in the Tropics: Case Study of Uganda. Atmosphere (BaseI), 9, 328. https://doi.org/10.3390/atmos9090328

[10] Sieck, L.C., Burges, S.J. and Steiner, M. (2007) Challenges in Obtaining Reliable Measurements of Point Rainfall. Water Resources Research, 43, W06701. https://doi.org/10.1029/2005WR004519

[11] Adam, J.C. and Lettenmaier, D.P. (2003) Adjustment of Global Gridded Precipitation for Systematic Bias. Journal of Geophysical Research: Atmospheres, 108, 4257. https://doi.org/10.1029/2002JD002499

[12] Chang, M. and Harrison, L. (2005) Field Assessments on the Accuracy of Spherical Gauges in Rainfall Measurements. Hydrological Processes, 19, 403-412. https://doi.org/10.1002/hyp.5539

[13] Mendelsohn, R., Kurukulasuriya, P., Basist, A., Kogan, F. and Williams, C. (2007) Climate Analysis with Satellite versus Weather Station Data. Climatic Change, 81, 71-83. https://doi.org/10.1007/s10584-006-9139-x

[14] Aghakouchak, A., Behrangi, A., Sorooshian, S., Hsu, K. and Amitai, E. (2011) Evaluation of Satellite-Retrieved Extreme Precipitation Rates across the Central United States. Journal of Geophysical Research, 116, D02115. https://doi.org/10.1029/2010JD014741

[15] Beck, H.E., et al. (2017) Global-Scale Evaluation of 22 Precipitation Datasets Using Gauge Observations and Hydrological Modeling. Hydrology and Earth System Sciences, 21, 6201-6217. https://doi.org/10.5194/hess-21-6201-2017

[16] Dembélé, M. and Zwart, S.J. (2016) Evaluation and Comparison of Satellite-Based Rainfall Products in Burkina Faso, West Africa. International Journal of Remote Sensing, 37, 3995-4014. https://doi.org/10.1080/01431161.2016.1207258

[17] Lo Conti, F., Hsu, K.L., Noto, L.V. and Sorooshian, S. (2014) Evaluation and Comparison of Satellite Precipitation Estimates with Reference to a Local Area in the 
Mediterranean Sea. Atmospheric Research, 138, 189-204.

https://doi.org/10.1016/j.atmosres.2013.11.011

[18] Hu, Z., Hu, Q., Zhang, C., Chen, X. and Li, Q. (2016) Evaluation of Reanalysis, Spatially Interpolated and Satellite Remotely Sensed Precipitation Data Sets in Central Asia. Journal of Geophysical Research: Atmospheres, 121, 5648-5663. https://doi.org/10.1002/2016JD024781

[19] Macharia, J.M., Ngetich, F.K. and Shisanya, C.A. (2020) Comparison of Satellite Remote Sensing Derived Precipitation Estimates and Observed Data in Kenya. Agricultural and Forest Meteorology, 284, Article ID: 107875. https://doi.org/10.1016/j.agrformet.2019.107875

[20] Peng, F., Zhao, S., Chen, C., Cong, D., Wang, Y. and Ouyang, H. (2020) Evaluation and Comparison of the Precipitation Detection Ability of Multiple Satellite Products in a Typical Agriculture Area of China. Atmospheric Research, 236, Article ID: 104814. https://doi.org/10.1016/j.atmosres.2019.104814

[21] Ferraris, L., Gabellani, S., Rebora, N. and Provenzale, A. (2003) A Comparison of Stochastic Models for Spatial Rainfall Downscaling. Water Resources Research, 39, 12. https://doi.org/10.1029/2003WR002504

[22] Verdin, A., Rajagopalan, B., Kleiber, W. and Funk, C. (2015) A Bayesian Kriging Approach for Blending Satellite and Ground Precipitation Observations. Water Resources Research, 51, 908-921. https://doi.org/10.1002/2014WR015963

[23] Uganda Second National Communication (SNC) (2014) Uganda Second National Communication to the United Nations Framework Convention on Climate Change. 213.

[24] Res, C., Vicente-Serrano, S.M., Saz-Sánchez, M.A. and Cuadrat, J.M. (2003) Comparative Analysis of Interpolation Methods in the Middle Ebro Valley (Spain): Application to Annual Precipitation and Temperature. Climate Research, 24, 161-180. https://doi.org/10.3354/cr024161

[25] Funk, C., et al. (2015) The Climate Hazards Infrared Precipitation with Stations-A New Environmental Record for Monitoring Extremes. Scientific Data, 2, 1-21. https://doi.org/10.1038/sdata.2015.66

[26] Katsanos, D., Retalis, A. and Tymvios, F. (2016) Analysis of Precipitation Extremes Based on Satellite (CHIRPS) and In Situ Dataset over Cyprus. Natural Hazards, 83, 53-63. https://doi.org/10.1007/s11069-016-2335-8

[27] Luo, X., Wu, W.Q., He, D.M., Li, Y.G. and Ji, X. (2019) Hydrological Simulation Using TRMM and CHIRPS Precipitation Estimates in the Lower Lancang-Mekong River Basin. Chinese Geographical Science, 29, 13-25.

https://doi.org/10.1007/s11769-019-1014-6

[28] Dinku, T., et al. (2018) Validation of the CHIRPS Satellite Rainfall Estimates over Eastern Africa. Quarterly Journal of the Royal Meteorological Society, 144, 292-312. https://doi.org/10.1002/qj.3244

[29] Shen, Z., et al. (2020) Recent Global Performance of the Climate Hazards Group Infrared Precipitation (CHIRP) with Stations (CHIRPS). Journal of Hydrology, 591, Article ID: 125284. https://doi.org/10.1016/j.jhydrol.2020.125284

[30] Duda, P.B., Hummel, P.R., Jr., A.S.D. and Imhoff, J.C. (2012) BASINS/HSPF: Model Use, Calibration, and Validation. Transactions of the ASABE, 55, 1523-1547. https://doi.org/10.13031/2013.42261

[31] Moriasi, D.N., Arnold, J.G., Van Liew, M.W., Bingner, R.L., Harmel, R.D. and Veith, T.L. (1983) Model Evaluation Guidelines for Systematic Quantification of Accuracy in Watershed Simulations. Transactions of the ASABE, 50, 885-900.

https://doi.org/10.13031/2013.23153 
[32] Gupta, H.V., Sorooshian, S. and Yapo, P.O. (1999) Status of Automatic Calibration for Hydrologic Models: Comparison with Multilevel Expert Calibration. Journal of Hydrologic Engineering, 4, 135-143.

https://doi.org/10.1061/(ASCE)1084-0699(1999)4:2(135)

[33] Coulibaly, M. and Becker, S. (2009) Spatial Interpolation of Annual Precipitation in South Africa-Comparison and Evaluation of Methods. Water International, 32, 494-502.

[34] Nimusiima, A., et al. (2013) Nature and Dynamics of Climate Variability in the Uganda Cattle Corridor. African Journal of Environmental Science and Technology, 7, 770-782. https://doi.org/10.5897/AJEST2013.1435

[35] Nsubuga, F.W. and Rautenbach, H. (2018) Climate Change and Variability: A Review of What Is Known and Ought to Be Known for Uganda. International Journal of Climate Change Strategies and Management, 10, 752-771.

https://doi.org/10.1108/IJCCSM-04-2017-0090

[36] Seong, C., Herand, Y. and Benham, B.L. (2015) Automatic Calibration Tool for Hydrologic Simulation Program-FORTRAN Using a Shuffled Complex Evolution Algorithm. Water (Switzerland), 7, 503-527. https://doi.org/10.3390/w7020503

[37] Barbosa, J.H.S., Fernandes, A.L.T., Lima, A.D., et al. (2019) The Influence of Spatial Discretization on HEC-HMS Modelling: A Case Study. International Journal of Hydrology, 3, 442-449. https://doi.org/10.15406/ijh.2019.03.00209 